\title{
Bacterial vaginosis in pregnancy: distribution of bacterial species in different gram-stain categories of the vaginal flora
}

\author{
ISOBEL J. ROSENSTEIN, D. J. MORGAN*, MARIE SHEEHAN*, R. F. LAMONT*† and D. TAYLOR- \\ ROBINSON
}

MRC Sexually Transmitted Diseases Research Group, St Mary's Hospital Medical School, Paddington, London W2 1PG, *Department of Obstetrics and Gynaecology, Northwick Park Hospital, Harrow, Middlesex HA1 3 UJ and $\dagger$ Institute of Obstetrics and Gynaecology, Royal Postgraduate Medical School, Ducane Road, London W12

\begin{abstract}
Vaginal swabs for microbiological culture were taken from 174 pregnant women whose vaginal flora had been evaluated by Gram's stain; 50 had grade III flora (bacterial vaginosis, BV), 50 grade II (intermediate), 41 had vaginal flora graded as abnormal which then reverted to grade I (revertants) and 33 had normal flora (controls). The aim was to determine whether bacterial species isolated from women with grade II flora differed from those with grade III flora. Isolation of Lactobacillus spp. decreased from grade I to grade III and that of other aerobic and anaerobic bacterial species increased. There was little difference in the species isolated from women with grade II and grade III flora, but there was a distinct order in which organisms in different species increased in numbers. The vaginal flora of revertants was intermediate between that of healthy controls and those with grade II flora. Coagulase-negative Staphylococcus spp. were isolated from a greater number of revertants than grade I controls but the incidence did not increase in grade II or grade III. Bifidobacterium spp. were isolated from a greater number of revertants than grade $I$ controls and increased further in grade II and grade III. However, Gardnerella vaginalis and Mycoplasma hominis were isolated from a much larger number of women with grade III flora than the other groups. The conclusion is that grade II is a transitional phase between grade I and grade III and that some organisms such as $G$. vaginalis and $M$. hominis only reach large numbers in the late stage. The sequence of appearance of the various bacterial species may be a result of the pathophysiological alteration of the vaginal ecosystem associated with BV.
\end{abstract}

\section{Introduction}

The normal vaginal bacterial flora of healthy premenopausal women consists predominantly of Lactobacillus spp. [1]. These are believed to play a protective role in guarding the urogenital tract against infection by pathogens [2]. In bacterial vaginosis (BV), a condition characterised by a raised vaginal $\mathrm{pH}$ and milky discharge, the normal vaginal flora is replaced by a mixed flora of aerobic, anaerobic and microaerophilic species [1]. Although BV is common, in the past it has been regarded as a harmless abnormality $[3,4]$. However, it is now considered to be associated with a variety of genital tract infections and complications including pelvic inflammatory disease, post-

Received 16 Aug. 1995; revised version accepted 18 Dec. 1995.

Corresponding author: Professor D. Taylor-Robinson, The Jefferiss Wing, St Mary's Hospital, Paddington, London W2 1PG. caesarean delivery endometritis, post-hysterectomy vaginal cuff infection, post-abortal sepsis, premature rupture of membranes and preterm labour and delivery [4-10]. In a recent study of pregnant women, those who had BV on screening in early pregnancy were five times more likely to have a preterm delivery or second trimester spontaneous abortion than those women who did not have BV [11].

BV may be diagnosed on clinical grounds if three of the following four criteria are fulfilled [12] (composite criteria): the presence of a homogeneous grey-white discharge; a vaginal $\mathrm{pH}>4.5$; vaginal epithelial cells covered with adherent bacteria ('clue' cells) in a 'wet mount' preparation; and the release of volatile amines by the addition of potassium hydroxide $5-10 \%$ to a small amount of vaginal fluid (the 'amine odour test'). The vaginal flora may also be assessed by Gram's stain of a smear prepared from a high vaginal swab [13-15]. Three categories may be recognised: grade I - normal, comprising predominantly lactobacillus 
morphotypes; grade II - intermediate, in which lactobacilli are reduced and mixed with other bacterial morphotypes; grade III - abnormal, with few or no lactobacillus morphotypes and with greatly increased numbers of other morphotypes, an appearance consistent with $\mathrm{BV}$ when diagnosed by clinical criteria. In a recent study by this group, the vaginal flora of women attending an antenatal clinic was graded in this way and an association was found between abnormal flora and an increased incidence of preterm delivery and late miscarriage [11]. A similar association between abnormal flora and preterm labour has been found by others [7, 16, 17] but not between BV and late miscarriage. There was also some indication in this study (unpublished observation) that preterm labour was most closely associated with grade III flora, whereas late miscarriage was associated with grade II flora. The current study was undertaken to determine by microbiological culture whether the bacterial species isolated from women with grade II and grade III flora are different or whether grade II simply represents a microbial continuum in the change from grade I to grade III and vice versa.

\section{Materials and methods}

\section{Study population}

Women attending the antenatal clinic at Northwick Park Hospital for the first time, at between 12 and 16 weeks and occasionally up to 20 weeks' gestation, were examined for evidence of $\mathrm{BV}$ as part of their routine antenatal examination. The diagnosis of BV was based on Gram's stain of vaginal secretion, as described previously [11].

The gram-stained slides were read after the clinic session. Women diagnosed as having abnormal flora (grade II or grade III) were asked to return to the clinic within 3 weeks to 1 month of their initial examination where they were examined again for evidence of abnormal flora by a Gram's stain of vaginal secretion. At this stage the women were also examined for clinical evidence of BV by the method described by Amsel et al. [12] (composite criteria). Women whose Gram's stain was still abnormal (grade II or grade III) were invited to enrol in a double-blind, placebo-controlled trial of a topically applied antibiotic cream (clindamycin 2\%) for the prevention of $\mathrm{BV}$-induced preterm delivery and early miscarriage. At the same time, high vaginal swabs were taken for full microbiological examination. Swabs were also collected from women who were described as 'revertants'. These women had an abnormal Gram's stain result on their first visit but, on returning to the clinic, their abnormal vaginal flora was found to have resolved spontaneously with a Gram's stain scored as grade I. In addition, there was no clinical evidence of BV as judged by composite criteria tests. Samples were also taken from women who had normal grade I flora on initial and subsequent screening and clinically had no evidence of $\mathrm{BV}$, and thus served as controls.

In this report, microbiological data are presented for 50 women with grade III flora and 50 women with grade II flora, randomly selected from the total population of women attending the antenatal clinic between January 1993 and March 1995, together with data from 41 revertants and 33 controls from the same population. Samples from a further 96 randomly selected women with BV were tested for Mycoplasma hominis and Ureaplasma urealyticum and samples from 50 of these women were also tested for Chlamydia trachomatis.

\section{Sampling}

The following swab specimens were obtained from the women. An endocervical swab for the detection of $C$. trachomatis was placed in sucrose-phosphate transport medium (Syva). An endocervical swab for the isolation of Neisseria gonorrhoeae was plated directly on to Modified New York City Medium (Oxoid). Plates were placed in a micro-aerophilic atmosphere (candle jar) and transported to the routine microbiology laboratory. They were then incubated in $\mathrm{CO}_{2} 6 \%$ at $37^{\circ} \mathrm{C}$ and examined after incubation for 24 and $48 \mathrm{~h}$. A high vaginal swab (HVS) for full microbiological culture was placed in bacteriological transport medium (tryptone $1 \%$, yeast extract $0.5 \%$, glucose $0.1 \%$ and cysteine hydrochloride $0.1 \%$ in sterile distilled water) and was agitated and squeezed thoroughly to dislodge its contents in the medium. The swab was then discarded and the transport medium was stored at $-70^{\circ} \mathrm{C}$ within $1 \mathrm{~h}$ of inoculation and cultured (by IJR) within 6 months of storage. A HVS for the detection of $M$. hominis and $U$. urealyticum was placed in mycoplasmal transport medium [18], agitated and squeezed into the medium and stored as described above. A HVS was collected for the detection of motile Trichomonas vaginalis by microscopic examination of a saline wet mount preparation.

\section{Processing of samples and detection of organisms}

C. trachomatis was detected by an enzyme immunoassay (MicroTrak, Syva), according to the manufacturer's instructions. For bacteriological examination of the samples, $0.1 \mathrm{ml}$ of the transport medium was plated on to each of the following media which were incubated at $37^{\circ} \mathrm{C}$ as follows: Columbia Agar (Oxoid) containing defibrinated horse blood $7 \%$, incubated aerobically for $48 \mathrm{~h}$, in a $\mathrm{CO}_{2}(6 \%)$ incubator for $48 \mathrm{~h}$ and anaerobically $\left(\mathrm{N}_{2} 80 \%, \mathrm{CO}_{2} 10 \%, \mathrm{H}_{2} \quad 10 \%\right)$ for 5 days; Rogosa Agar (Oxoid) incubated microaerophilically and anaerobically for the isolation of lactobacilli; Brain Heart Infusion Agar (Oxoid), to which was added vancomycin $7.5 \mu \mathrm{g} / \mathrm{ml}$, paromomycin $100 \mu \mathrm{g} / \mathrm{ml}$ (Parke Davis and Co.) and laked horse blood $10 \%$, for the isolation of anaerobic gram-negative rods. 
Different colony types were recorded and subjected to semi-quantitation as follows: few $=1-30$ colonies at inoculum site; $+=$ heavy growth at inoculum site and $\leqslant 10$ colonies at first streak; $++=$ heavy growth at inoculum site and first streak and $\leqslant 10$ colonies at second streak; $+++=$ heavy growth at inoculum site and first streak and second streak and $\leqslant 10$ colonies at third streak; $++++=$ heavy growth at inoculum site and first, second and third streak and $\leqslant 10$ colonies at fourth streak.

A colony of each type was subcultured on to Columbia blood agar. All organisms were identified presumptively by their morphology with Gram's stain. Colonies from anaerobic plates were subcultured in the same way and then incubated aerobically and anaerobically. Organisms that produced colonies that developed only anaerobically from two subcultures were considered to be anaerobic. All anaerobic organisms were identified presumptively by their morphology on Gram's stain. For coagulase production, colonies of aerobic, catalase-positive, grampositive cocci were inoculated into nutrient broth containing plasma $10 \%$ and clotting was observed after $4 \mathrm{~h}$.

For identification of $M$. hominis and $U$. urealyticum, $0.1 \mathrm{ml}$ of transport medium was added to $0.9 \mathrm{ml}$ of broth containing urea or arginine with phenol red as a $\mathrm{pH}$ indicator [18]. Further 10-fold dilutions were made up to 1 in $10^{8}$ for $M$. hominis and 1 in $10^{6}$ for $U$. urealyticum and the cultures were observed daily for 7 days for evidence of a colour change. The highest dilution (titre) at which a colour change occurred was considered to contain one colourchanging unit.

\section{Results}

The incidence of micro-organisms not recognised as part of the microbial flora of $\mathrm{BV}$, namely $C$. trachomatis, $N$. gonorrhoeae and $T$. vaginalis, is shown in Table 1. $N$. gonorrhoeae was not isolated from any of the four groups of women and trichomonads were detected rarely. Chlamydiae were detected most often in the BV group (12\%). However, when the results of a further 50 women with $\mathrm{BV}$ from the same antenatal population were included for analysis, the incidence of chlamydiae fell to $6 \%$.

\section{Distribution of micro-aerophilic and aerobic flora}

The median number of micro-aerophilic and aerobic bacterial species isolated from each group was 2 (range 0-5) for grade I controls, 3 (range 0-5) for grade I revertants, 3 (range 0-5) for grade II and 4 (range $1->5$ ) for grade III.

Although there was a reduction in the incidence of lactobacilli from grade I to grade III flora, they were isolated from a substantial proportion of women with grade II and grade III flora $(66 \%$ and $38 \%$, respectively), sometimes in quite large numbers (Fig. 1). Conversely, lactobacilli were not isolated from $9 \%$ of women in the control group and from $22 \%$ in the revertant group, the latter reflecting perhaps in some instances a change back to clinical normality ahead of regaining a normal flora or, in other instances, a discrepancy between culture and Gram's stain results.

The bacterial flora pattern demonstrated by the revertant group was intermediate between that demonstrated by the healthy controls and those in the grade II flora group (Table 2). Due to initial difficulty with culture conditions, the results for $G$. vaginalis isolation were valid only for a proportion of specimens. Nevertheless, it was clear that $G$. vaginalis was isolated more frequently from women with grade III flora $(72 \%)$ than from women in any other group $(\leqslant 6 \%)$.

The proportion of women from whom various aerobic bacterial species were isolated increased from that for the grade I controls through the various grades to grade III (Table 2). This was seen particularly with Corynebacterium spp., coagulase-negative staphylococci and Streptococcus spp., although the former two were found in a large proportion of healthy grade I controls. Candida spp. were isolated from more women in the grade I and II groups and in larger numbers in the grade I revertants and grade II groups (data not shown) than the grade III group.

Of the 'enteropharyngeal' species, $\beta$-haemolytic streptococci were the only organisms isolated more

Table 1. Isolation of $C$. trachomatis, $N$. gonorrhoeae and $T$. vaginalis from women with $\mathrm{BV}$ and healthy controls

\begin{tabular}{lcccc}
\hline & & Isolation from women with Gram's stain of \\
\cline { 2 - 5 } & $\begin{array}{c}\text { Grade I } \\
\text { (healthy) } \\
\mathrm{n}=33\end{array}$ & $\begin{array}{c}\text { Grade I } \\
\text { (revertants) } \\
\mathrm{n}=41\end{array}$ & $\begin{array}{c}\text { Grade II } \\
\text { (intermediate) } \\
\mathrm{n}=50\end{array}$ & $\begin{array}{c}\text { Grade III } \\
(\mathrm{BV})\end{array}$ \\
\hline C. trachomatis & $0 / 12$ & $1(2 \%)$ & $2(4 \%)$ & 0 \\
N. gonorrhoeae & $0 / 8$ & $0 / 30$ & $6(12 \%)$ & 0 \\
$T$. vaginalis & $1(3 \%)$ & 0 & $3(6 \%)$ & 0 \\
\hline
\end{tabular}




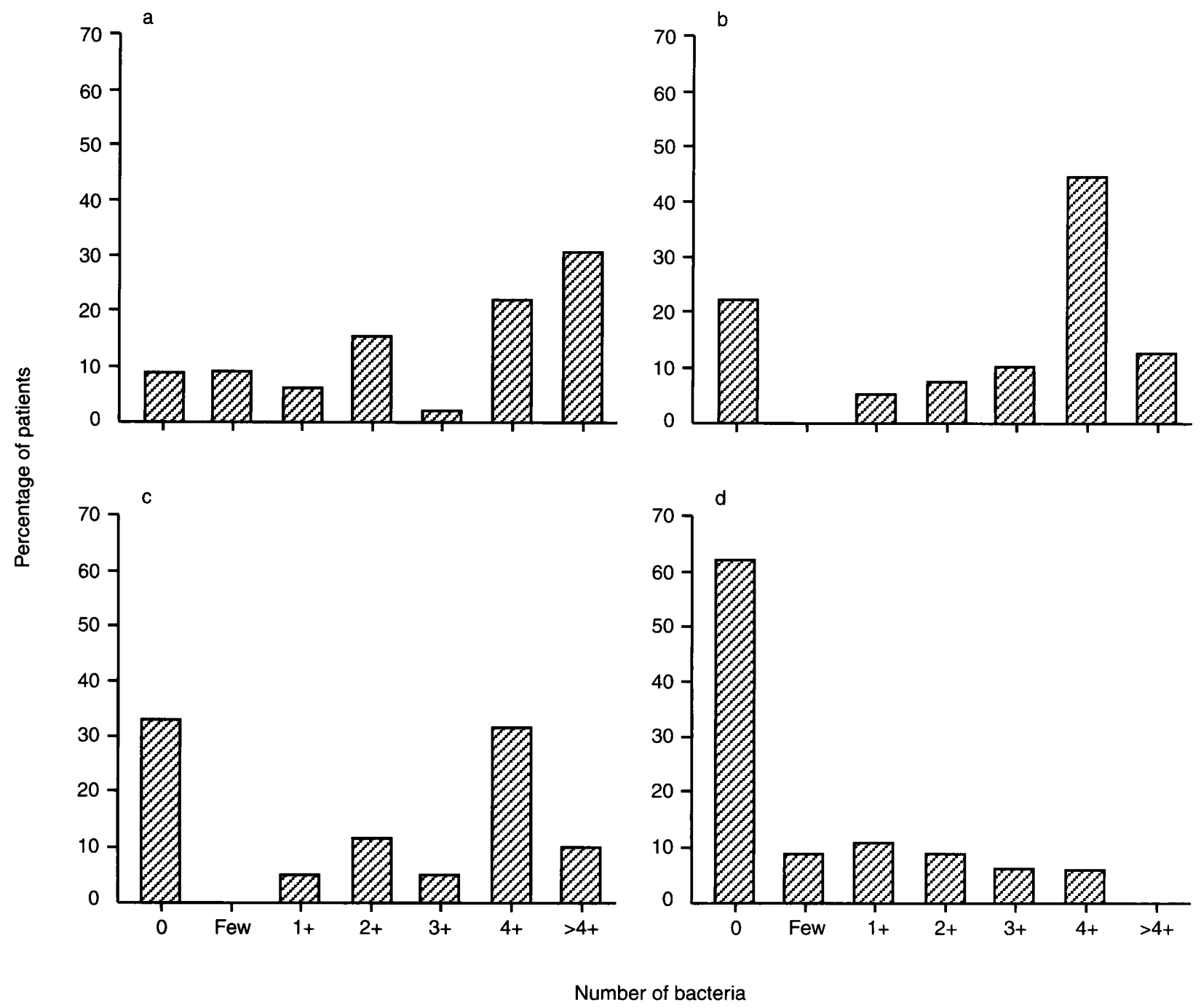

Fig. 1. Distribution of Lactobacillus spp. in women with BV and healthy controls: a, grade I, healthy controls; b, grade I, revertants; c, grade II; d, grade III.

Table 2. Distribution of micro-aerophilic and aerobic flora in women with BV and healthy controls

\begin{tabular}{|c|c|c|c|c|}
\hline \multirow[b]{2}{*}{ Micro-organisms } & \multicolumn{4}{|c|}{ Number (\%) of women with the micro-organism in the following categories } \\
\hline & $\begin{array}{c}\text { Grade I } \\
\text { (healthy controls) } \\
\mathrm{n}=33\end{array}$ & $\begin{array}{c}\text { Grade I } \\
\text { (revertants) } \\
\mathrm{n}=41\end{array}$ & $\begin{array}{c}\text { Grade II } \\
\text { (intermediate) } \\
n=50\end{array}$ & $\begin{array}{l}\text { Grade III } \\
(B V) \\
n=50\end{array}$ \\
\hline \multicolumn{5}{|l|}{ Micro-aerophilic flora } \\
\hline Lactobacillus spp. & $30(91 \%)$ & $32(78 \%)$ & $33(66 \%)$ & $19(38 \%)$ \\
\hline G. vaginalis & $1 / 21(5 \%)$ & $1 / 17(6 \%)$ & $2 / 38(5 \%)$ & $13 / 18(72 \%)$ \\
\hline \multicolumn{5}{|l|}{ Aerobic flora } \\
\hline Corynebacterium spp. & $12(36 \%)$ & $21(51 \%)$ & $28(56 \%)$ & $42(84 \%)$ \\
\hline Coagulase-negative & $19(58 \%)$ & $32(78 \%)$ & $39(78 \%)$ & $37(74 \%)$ \\
\hline \multicolumn{5}{|l|}{ Staphylococcus spp. } \\
\hline Staph. aureus & $3(9 \%)$ & $3(7 \%)$ & $4(8 \%)$ & $7(14 \%)$ \\
\hline Streptococcus spp.* & $3(9 \%)$ & $7(17 \%)$ & $18(36 \%)$ & $28(56 \%)$ \\
\hline Streptococcus spp. $\dagger$ & 0 & 0 & $6(12 \%)$ & $2(4 \%)$ \\
\hline Gram-negative rods & 0 & $3(7 \%)$ & $5(10 \%)$ & $6(12 \%)$ \\
\hline Candida spp. & $7(21 \%)$ & $14(34 \%)$ & $13(26 \%)$ & $7(14 \%)$ \\
\hline
\end{tabular}

${ }^{*} \alpha$-Haemolytic and non-haemolytic on Columbia blood agar.

$\dagger \beta$-Haemolytic on Columbia blood agar. 
frequently from women with grade II flora than from those with grade III flora (Table 2).

\section{Distribution of anaerobic flora}

The median number of anaerobic species isolated was 0 (range $0-3$ ) for grade I controls, 0 (range $0-3$ ) for grade I revertants, 2 (range $0-5$ ) for grade II and 3 (range 1-5) for grade III.

Anaerobic bacteria were isolated far more often and in larger numbers (not shown) from women with grade II or grade III flora than from those with grade I flora (Table 3). Anaerobic gram-positive cocci and anaerobic gram-negative rods were isolated from a larger proportion of women in the grade III group than from those in the other groups. However, Bifidobacterium spp. were isolated from a much larger proportion of the revertants and those in the grade II group, compared with the isolation of anaerobic cocci and rods in these groups and from nearly $100 \%$ of women in the grade III group. Conversely, $M$. hominis was isolated from a much larger proportion of women with grade III flora compared with the revertants and those with grade II flora (Table 3). The proportion of women with $U$. urealyticum increased from grade I to grade III, but the difference was not as striking as that seen for M. hominis. U. urealyticum was isolated from a substantial proportion of the healthy women $(42 \%)$ compared with the low isolation rate of $M$. hominis $(6 \%)$

A further 96 specimens from women with abnormal Gram's stain results (five of grade II and 91 of grade III) from the same antenatal population were tested for $U$. urealyticum and $M$. hominis. Analysis of larger numbers confirmed the difference in the distribution of these two micro-organisms seen previously. Thus, $U$. urealyticum was isolated from $49 \%$ of women with grade II flora and from $59 \%$ of those with grade III flora, whereas $M$. hominis was isolated from $14.5 \%$ of women with grade II flora and from $52 \%$ of those with grade III flora. The numbers of $M$. hominis organisms in specimens from the four groups are shown in Fig. 2, large numbers occurring predominantly in women with grade III flora.

\section{Sequence of changes in the flora}

Fig. 3 illustrates the changes that might occur in the microbial flora of the vagina, culminating in BV. The increase in colonisation by coagulase-negative staphylococci occurred at an early stage (grade I revertants) but did not increase further. In contrast, other bacteria such as Bifidobacterium spp. appeared early (grade I revertants) and continued to increase in grades II and III, while other species, such as $G$. vaginalis and $M$. hominis, were only found in large numbers of patients in the late stage (grade III).

\section{Discussion}

The vaginal microbial flora in pregnancy has been studied previously in relation to preterm delivery, miscarriage and intra-uterine growth retardation $[7,8$, $10,11,17,19]$. The current study, which to our knowledge is the most extensive and detailed in the UK of the microbiology of BV in pregnancy, was undertaken to determine whether differences exist between the bacterial species isolated from the vagina of pregnant women with grade II flora compared with those isolated from women with grade III flora. The recognition of a group of women defined as 'revertants' is novel and is not in the pattern of vaginal flora described by Hillier et al. [15]. Nevertheless, the results of the present study are consistent with those of these workers in demonstrating that the flora can switch from the abnormal state (graded as III) to the normal state (graded as I), passing through an intermediate stage (graded as II). This can occur rapidly, within 3-4 weeks, as the revertant group of 41 women observed contained four whose flora changed from grade III to grade I between clinic visits. The flora of the other 37 women changed from grade II to grade I.

Table 3. Distribution of $M$. hominis, $U$. urealyticum and anaerobic flora in women with $\mathrm{BV}$ and in healthy controls

\begin{tabular}{|c|c|c|c|c|}
\hline \multirow[b]{2}{*}{ Micro-organisms } & \multicolumn{4}{|c|}{ Number $(\%)$ of women with the micro-organism in the following categories } \\
\hline & $\begin{array}{c}\text { Grade I } \\
\text { (healthy controls) } \\
n=33\end{array}$ & $\begin{array}{c}\text { Grade I } \\
\text { (revertants) } \\
n=41\end{array}$ & $\begin{array}{c}\text { Grade II } \\
\text { (intermediate) } \\
\mathrm{n}=50\end{array}$ & $\begin{array}{c}\text { Grade III } \\
\text { (BV) } \\
n=50\end{array}$ \\
\hline M. hominis & $2(6 \%)$ & $7(17 \%)$ & $7(14 \%)$ & $29(58 \%)$ \\
\hline U. urealyticum & $14(42 \%)$ & $21(51 \%)$ & $25(50 \%)$ & $34(68 \%)$ \\
\hline \multicolumn{5}{|l|}{ Anaerobic flora } \\
\hline Gram-positive cocci* & $5(15 \%)$ & $7(17 \%)$ & $20(40 \%)$ & $37(74 \%)$ \\
\hline Gram-negative rods ${ }^{\dagger}$ & $3(9 \%)$ & $10(24 \%)$ & $21(42 \%)$ & $33(66 \%)$ \\
\hline Bifidobacterium spp. & $4(12 \%)$ & $17(41 \%)$ & $29(58 \%)$ & $47(94 \%)$ \\
\hline Other gram-positive rods ${ }^{\ddagger}$ & $5(15 \%)$ & $6(15 \%)$ & $9(18 \%)$ & $24(48 \%)$ \\
\hline
\end{tabular}

*Peptococcus spp., Peptostreptococcus spp.

${ }^{\dagger}$ Bacteriodes spp., Prevotella spp., Fusobacterium spp

${ }^{\ddagger}$ Mobiluncus spp., Propionibacterium spp. 


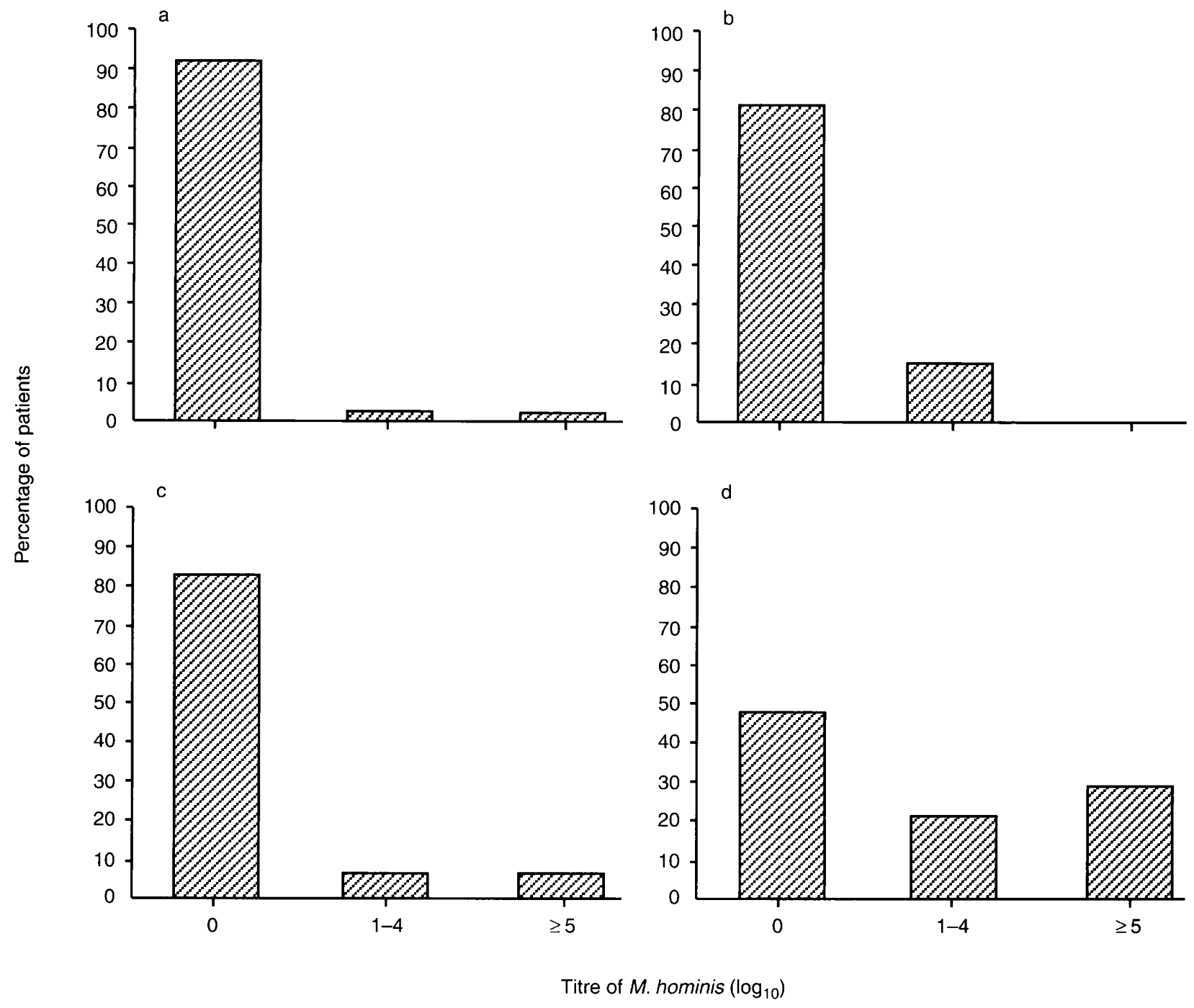

Fig. 2. Distribution of $M$. hominis in women with $\mathrm{BV}$ and healthy controls: a, grade $\mathrm{I}$, healthy controls; b, grade I, revertants; c, grade II; d, grade III.

Although the type of organisms isolated from women with grade II and grade III flora may not be different, there does appear to be an order in which the different species appear. This is illustrated clearly in Fig. 3 and has not been highlighted by others. As expected, a large proportion of healthy women with grade I flora had lactobacilli in large numbers. Coagulase-negative staphylococci were often present, as were Corynebacterium spp. and $U$. urealyticum. In the revertant group, compared with women who had grade I flora, a much larger proportion carried coagulase-negative staphylococci and Bifidobacterium spp. in large numbers. The proportion of women with grade II flora from whom Bifidobacterium spp. were recovered was greater than that of the revertant group, as was the proportion of women with grade II flora carrying anaerobic grampositive cocci and anaerobic gram-negative rods. In contrast, the proportion of women with coagulasenegative staphylococci in the two groups was similar. It was only in grade III that $G$. vaginalis and $M$. hominis were found in a large proportion of the women. Like us, Hillier et al. [15] recorded a high incidence of $U$. urealyticum in the normal grade I group, an incidence which increased steadily through the intermediate to the BV group. However, unlike these workers, this study found that the incidence of $G$. vaginalis and $M$. hominis did not increase steadily, but the organisms were isolated almost uniquely in the grade III group.

It is clear from the results of this study that the initial disturbance in the vagina causes certain bacteria, such as coagulase-negative staphylococci, to appear first, in large numbers, followed by Bifidobacterium spp. However, it is then unclear whether rapid multiplication of these organisms provides an environment conducive to the multiplication of other bacterial species, such as anaerobic gram-negative rods and gram-positive cocci, and then finally $G$. vaginalis and $M$. hominis, or whether it is the alteration of the environment per se which causes this sequence of events to occur. Examination of physiological factors, 


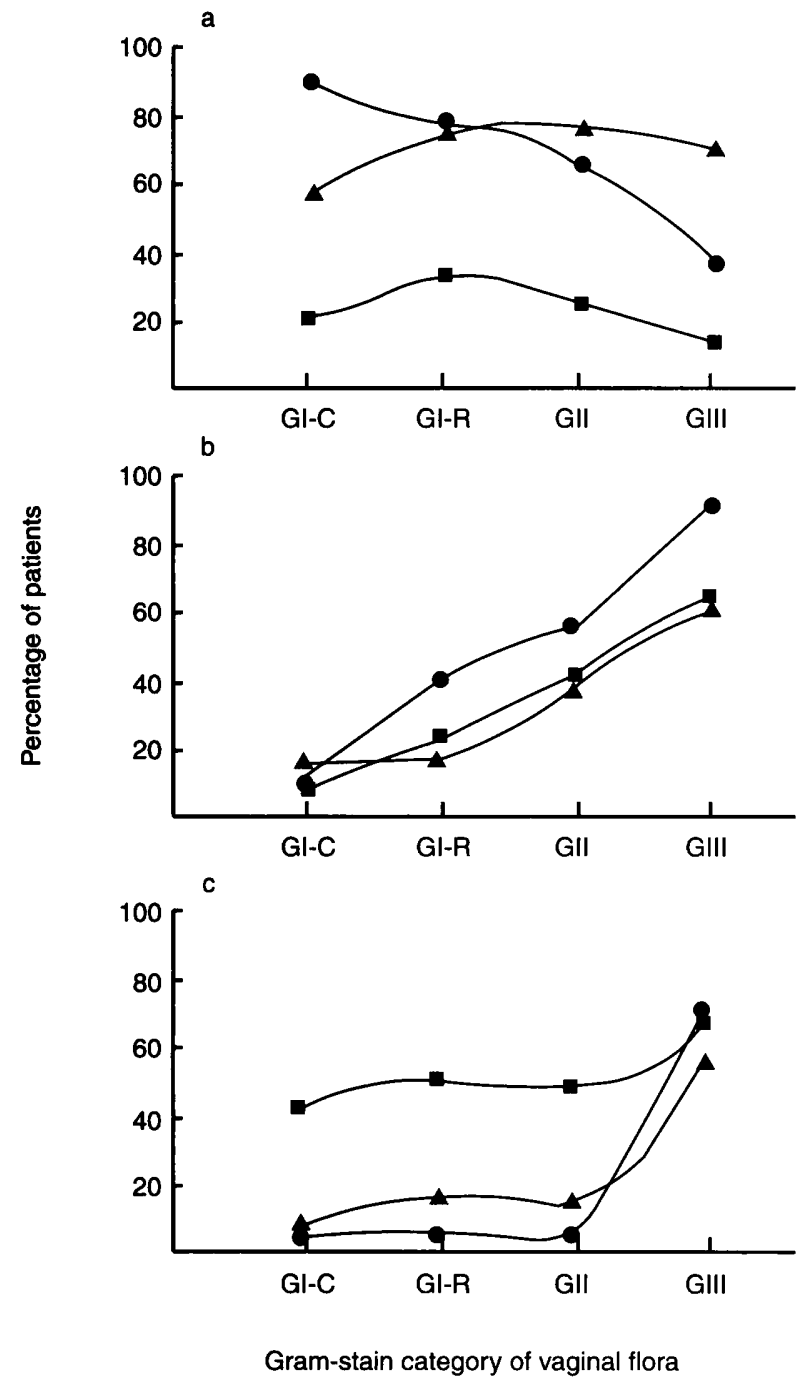

Fig. 3. Percentage incidence of various BV-associated bacterial species in different gram-stain categories of the vaginal flora. a, $\boldsymbol{\ominus}$, Lactobacillus spp.; $\boldsymbol{\Delta}$, coagulasenegative Staphylococcus spp.; $\mathbf{\square}$, Candida spp.; b, $\mathbf{0}$ Bifidobacterium spp.; $\boldsymbol{\Lambda}$, anaerobic gram-positive cocci; $\boldsymbol{\square}$, anaerobic gram-negative rods; c, $\boldsymbol{O}, G$. vaginalis; $\boldsymbol{\Lambda}$, M. hominis; $\mathbf{\square}$, U. urealyticum.

such as hormone and secreted immunoglobulin concentrations in the vagina, might help to distinguish between the two possibilities although, of course, they may not be mutually exclusive.

This work was supported by a Research Grant from WellBeing. We thank Nicola Wilson-Smith for the preparation of this manuscript.

\section{References}

1. Hill GB, Eschenbach DA, Holmes KK. Bacteriology of the vagina. Scand J Urol Nephrol 1985; Suppl 86: 23-39.

2. Reid G, Bruce AW, McGroarty JA, Cheng KJ, Costerton JW. Is there a role for lactobacilli in prevention of urogenital and intestinal infections? Clin Microbiol Rev 1990; 3: 335-344.

3. Mead PB. Epidemiology of bacterial vaginosis. Am J Obstet Gynecol 1993; 169: 446-449.

4. Eschenbach DA, Hillier S, Critchlow C, Stevens C, DeRouen T, Holmes KK. Diagnosis and clinical manifestations of bacterial vaginosis. Am J Obstet Gynecol 1988; 158: 819-828.

5. Watts DH, Krohn MA, Hillier SL, Eschenbach DA. Bacterial vaginosis as a risk factor for post-cesarean endometritis. Obstet Gynaecol 1990; 75: 52-58.

6. Soper DE, Bump RC, Hurt WG. Bacterial vaginosis and trichomoniasis vaginitis are risk factors for cuff cellulitis after abdominal hysterectomy. Am J Obstet Gynecol 1990; 163: 1016-1023.

7. Gravett MG, Nelson HP, DeRouen T, Critchlow C, Eschenbach $\mathrm{DA}$, Holmes KK. Independent associations of bacterial vaginosis and Chlamydia trachomatis infection with adverse pregnancy outcome. J Am Med Assoc 1986; 256: 1899-1903.

8. Lamont RF, Taylor-Robinson D, Newman M, Wigglesworth J, Elder MG. Spontaneous early preterm labour associated with abnormal genital bacterial colonization. $\mathrm{Br} J$ Obstet Gynaecol 1986; 93: 804-810.

9. Lamont RF. Bacterial vaginosis. In: Studd J (ed) 1994 Yearbook of the Royal College of Obstetricians \& Gynaecologists. London: Parthenon Publishing Group. 1995; 149-160.

10. Lamont RF, Taylor-Robinson D, Wigglesworth JS, Furr PM, Evans RT, Elder MG. The role of mycoplasmas, ureaplasmas and chlamydiae in the genital tract of women presenting in spontaneous early preterm labour. J Med Microbiol 1987; 24: 253-257.

11. Hay PE, Lamont RF, Taylor-Robinson D, Morgan DJ, Ison C, Pearson J. Abnormal bacterial colonisation of the genital tract and subsequent preterm delivery and late miscarriage. $B M J$ 1994; 308: 295-298.

12. Amsel R, Totten PA, Spiegel CA, Chen KCS, Eschenbach DA, Holmes KK. Nonspecific vaginitis: diagnostic criteria and microbial and epidemiologic associations. Am J Med 1983; 74: 14-22.

13. Spiegel CA, Amsel R, Holmes KK. Diagnosis of bacterial vaginosis by direct Gram stain of vaginal fluid. $J$ Clin Microbiol 1983; 18: 170-177.

14. Nugent RP, Krohn MA, Hillier SL. Reliability of diagnosing bacterial vaginosis is improved by a standardized method of gram stain interpretation. J Clin Microbiol 1991; 29: 297-301.

15. Hillier SL, Krohn MA, Nugent RP, Gibbs RS for the Vaginal Infections and Prematurity Study Group. Characteristics of three vaginal flora patterns assessed by Gram stain among pregnant women. Am J Obstet Gynecol 1992; 166: 938-944.

16. McDonald HM, O'Loughlin JA, Jolley $P$, Vigneswaran $R$, McDonald PJ. Vaginal infection and preterm labour. $B r J$ Obstet Gynaecol 1991; 98: 427-435.

17. Holst E, Rossel Goffeng A, Andersch B. Bacterial vaginosis and vaginal microorganisms in idiopathic premature labor and association with pregnancy outcome. J Clin Microbiol 1994; 32: 176-186.

18. Taylor-Robinson D. Genital mycoplasma infections. Clin Lab Med 1989; 9: 501-523.

19. Germain M, Krohn MA, Hillier SL, Eschenbach DA. Genital flora in pregnancy and its association with intrauterine growth retardation. J Clin Microbiol 1994; 32: 2162-2168. 